Vascular Birthmarks: Pathogenesis and Management. Edited by T J Ryan and G W Cherry. (Pp 203; £30). Oxford: Oxford University Press. 1987.

This book sets out to ensure that up to date information about the pathogenesis and management of haemangiomas is shared between the many specialists to whom patients with a birthmark are referred. In this, it succeeds admirably. There are 10 authors (the length and style of the 12 chapters varies accordingly!). Different specialities have suggested different classifications, which has hindered communication. The first chapter, therefore, is the longest (54 pages) and proposes a classification according to a combination of clinical and histopathological features and capacity for dynamic growth and involution illustrated with electron and conventional micrographs. Clinical course is described in two chapters. Moroz reports on 1600 children with vascular birthmarks and highlights the association with prematurity, and Bowers confirms that for the majority treatment should be conservative. However, he emphasises cases where early interference is justified (for instance eye involvement).

Six chapters discuss active treatment: the role of corticosteroids (apparently helpful only in actively growing strawberry haemangiomata), Argon laser and other treatments of port wine stains, surgery, and selective vessel embolisation. As haemangioma and lymphangioma commonly occur together there is a short chapter on malformations of lymphatic vessels.

So what would especially interest a clinical geneticist, as on the top of page two you will find ". . . there is no evidence for a genetic predisposition"? The second largest chapter (33 pages) is on the differential diagnosis of "abnormal cutaneous vascular patterns" and has tables of acquired and inherited conditions associated with telangiectasia, skin atrophy, premature ageing, port wine stains, accentuated but normal blood flow patterns, and palpable haemangiomas. These provide an overview and are useful as an aide memoire. A short paragraph on each condition is found in the main text supported by over 170 references, which include references to those families with a dominant pattern of inheritance. Unfortunately, the same typeface is used for the section, subsection, and paragraph headings, which is extremely confusing in trying to decide to which subgroup a particular piece of information is related. Naturally, too, there is overlap between this chapter and the same conditions described elsewhere in the book, but this usually adds to the information rather than confuses. The index is incomplete and erratic (for example, some syndromes are indexed under 'syndrome' and some under their eponyms) and there are more typographical errors than one would expect. Redemption is achieved by the final chapter, which should also interest the thinking geneticist, on research into haemangioma development, speculating on the role of endothelial cell type and maturity, factor VII related antigen, and some 'candidate' genes. How refreshing to ask "why" and "how", even if answers are not immediately forthcoming.

Peter A Farndon

\section{Informative Morphogenetic Variants in the Newborn} Infant

By K Méhes. (Pp 228; £11·50.) Budapest: Akadémiai Kiadó. 1988.

This is the second edition of this small book, originally published in 1983. It is based on the author's examination of thousands of newborns.

For each variation, the incidence, inheritance, definition and diagnosis, and clinical significance is given. Where associated with syndromes a list is given.

The main use of the book is in defining and giving an incidence in newborn populations of the variants. I do not think giving a list of, often exceedingly rare, syndromes without any supplementary information is useful. After each variant references are given and most are up to date and accessible.

This is a useful little book that will be helpful to those learning dysmorphology both for the definitions and for the short introductory chapters.

\section{Donnai}

Prader-Willi Syndrome: Selected Research and Management Issues

Edited by Mary Lou Caldwell and Ronald L Taylor. (Pp 110; DM 85.) Berlin, Heidelberg: Springer Verlag. 1988.

One estimate puts the incidence of the Prader-Willi 